\title{
Elementos fundamentais do presidencialismo de coalizão
}

\author{
Key elements of the coalization presidentialism
}

Maicy Maia

Universidade Federal do Maranhão - UFMA

Kassianne Mendes Silva

Universidade Federal do Maranhão - UFMA

RESUMO O presente artigo consiste em revisão bibliográfica sobre os principais fundamentos do presidencialismo que se desenvolveu em solo brasileiro, cuja basal principal característica é a coalizão, ou seja, a realização de alianças, destinadas, em tese, à garantia da governabilidade. Busca-se examinar os elementos do federalismo, sistema eleitoral proporcional e de lista aberta e o multipartidarismo, com o fim de melhor compreender e avaliar as coalizões efetuadas pelos Poder Executivo. Para o desenvolvimento do estudo, utilizou-se o método dedutivo, a abordagem descritivo-exploratória e a aplicação das técnicas de pesquisa bibliográfica e documental.

Palavras-chave: Presidencialismo de coalizão. Fundamentos. Democracia.

Abstract This article consists of a bibliographic review on the main fundamentals of presidentialism that developed on Brazilian soil, whose main characteristic is the coalition, that is, the realization of alliances, aimed, in theory, at ensuring governance. It seeks to examine the elements of federalism, the proportional and open list electoral system and the multiparty system, in order to better understand and evaluate the coalitions made by the Executive Power. For the development of the study, the deductive method, the descriptiveexploratory approach and the application of bibliographic and documentary research techniques were used.

Keywords: Coalition presidentialism. Fundamentals. Democracy.

\section{1 - INTRODUÇÃo}

Nos últimos tempos, o tema "presidencialismo de coalizão" tem sido recorrente nos veículos de mídia e na vida do brasileiro. $\mathrm{O}$ assunto vem se popularizando desde o primeiro 
mandato (2011-2014) da ex-presidente Dilma Rousseff e, definitivamente, ganhou força após a reeleição daquela (2015-2016), quando se observou o alinhamento de fatores políticos e econômicos que contribuíram para o fortalecimento das rivalidades entre antigos parceiros políticos.

Esses fatores orbitavam desde a percepção de antigos partidos políticos - como PT e PMDB - de que tinham boas chances de ampliar o controle sobre Estados importantes em que atuavam como polos opositores ao governo; a existência de claros sinais de enfraquecimento da presidência, cuja popularidade entrou em queda, dado o desempenho econômico medíocre, a inflação em persistente alta e, finalmente, o surgimento de alternativas políticas viáveis para opor-se à então Chefe do Poder Executivo (ABRANCHES, 2014).

À época, as opiniões se dividiram. Parte dos veículos de comunicação e especialistas $^{1}$ atribuiu o processo de impeachment da ex-presidente Dilma Rousseff ao rompimento com as suas bases aliadas, que a levou à crise de governabilidade e às grandes dificuldades enfrentadas junto ao Congresso Nacional. Outra parcela, no entanto, entendeu que o impeachment de Dilma Rousseff envolveu fatores bem mais complexos, ultrapassando a seara da ingovernabilidade e instabilidade política, ancorado na inadequação do governo da presidente à Lei de Responsabilidade Fiscal ${ }^{2} \mathrm{e}$ às "pedaladas fiscais". ${ }^{3}$

O que se observa de forma muito clara é que, em todas as perspectivas, o presidencialismo de coalizão é referenciado e, por isso, é fundamental perceber esse arranjo institucional. No entanto, para melhor entendê-lo, é necessário compreender os seus elementos fundamentais e a forma como eles se desenvolvem no contexto brasileiro.

Pensando nisso, o presente estudo examina o federalismo, o sistema eleitoral proporcional e de lista aberta, assim como o multipartidarismo, em sua trajetória histórica e como se desenvolveram e adaptaram em solo brasileiro. Apenas com a compreensão desses elementos básicos do presidencialismo brasileiro é que se pode pretender o estudo do presidencialismo de coalizão.

Nos Estados democráticos, a coalizão é um meio utilizado pelos governos para assegurar a governabilidade, pautando-se na estreita relação entre os atores dos poderes Executivo e Legislativo. A expressão "presidencialismo de coalizão" foi cunhada por Abranches (1988) e consiste em uma peculiaridade do sistema político brasileiro, pois combina presidencialismo, multipartidarismo, federalismo e sistema proporcional de lista aberta. Apesar de autores como LIMONGI (2006) não compartilharem da dita originalidade dessa característica do nosso sistema político, é inegável que a política brasileira se desenrola sob a toada do presidencialismo de coalizão.

Scott Mainwaring (1993), em seus estudos, debruçou-se sobre a política brasileira e observou a dificuldade para manter uma democracia presidencialista e multipartidária.

1 Como o referencial teórico deste artigo, qual seja, Sérgio Henrique Abranches, em artigo intitulado "Os ciclos do presidencialismo de coalizão", publicado em 2014, em que atribui a referida crise ao relacionamento entre o PT e o PMDB, e consequente desestabilização da coalizão presidencial, que descortinavam a persistência de certos traços do presidencialismo de coalizão. Apesar disso, o autor entende que os veículos de comunicação não deram muita importância a outros elementos que fazem parte dessa mesma dinâmica.

2 Ao conceder créditos suplementares sem autorização do Congresso Nacional, em 2015.

3 Conforme "A LEGISLAÇÃO ORÇAMENTÁRIA EM XEQUE COM ÊNFASE NO CASO DAS PEDALADAS FISCAIS. Disponível em: $<\mathrm{http}: / /$ sisweb.tesouro.gov.br/apex/cosis_monografias.obtem_monografia?p_id=736> 
Para o autor, essas características são fontes de instabilidade, principalmente pelo sistema eleitoral que proporciona a fragmentação partidária e a extrema indisciplina e indulgência dos partidos brasileiros, circunstâncias que dificultam a obtenção da maioria no Congresso Nacional pelo presidente. A conjugação desses fatores em um contexto de adversidade tem potencial para que, até o mais popular dos presidentes perca a empatia da sociedade, forçando-o a realizar coalizões governamentais capazes de criar uma base de sustentação minimamente estável para a concretização da sua agenda.

Como se percebe, o tema é bastante extenso, pois envolve tantas variáveis, que é necessário dissecá-lo minunciosamente. É o que pretende este artigo: iniciar o referido estudo e examinar os elementos fundamentais do presidencialismo de coalizão, quais sejam, o federalismo, o sistema eleitoral proporcional e de lista aberta, o multipartidarismo e a forma como eles se desenvolvem no Brasil.

Para tanto, lançou-se mão do método dedutivo, da abordagem descritivo-exploratória do tema e da aplicação das técnicas de pesquisa bibliográfica e documental na legislação pertinente.

\section{2 - Presidencialismo: Origem e CARACTERísticas gerais}

A compreensão do presidencialismo de coalizão demanda a assimilação do sistema presidencialista. Inicialmente, deve-se entender que os sistemas de governo são a forma como os poderes se relacionam, dado o nível de separação entre eles. Dallari (2012) explica que as relações entre os poderes Executivo e Legislativo determinaram a existência de dois sistemas de governo: o parlamentarismo e o presidencialismo, que constituem as principais tendências nos Estados contemporâneos.

O sistema presidencialista tem origem na Constituição dos Estados Unidos da América, aprovada pela Convenção da Filadélfia, em 1787. Comparado ao parlamentarismo, o presidencialismo não é fruto de um modelo teórico prévio, nem resulta de um longo processo de elaboração (DALLARI, 2012).

Os Estados Unidos da América seguiram fortemente a teoria montesquiana da separação dos poderes, ${ }^{4}$ com a finalidade de combater o absolutismo ou qualquer forma de concentração do poder, evitando a repetição da experiência inglesa, país de onde foram colônia. A própria experiência de submissão à monarquia inglesa fez que o presidencialismo fosse instituído e rigorosamente controlado pelo sistema de freios e contrapesos (DALLARI, 2012). Segundo Carvalho e Maia (2019), o maior desafio para a Convenção da Filadélfia (1787) era equilibrar as liberdades individuais e a independência dos demais poderes, com a força que o chefe do Poder Executivo precisava ter para lidar com os problemas que os Estados Unidos atravessavam naquele momento.

4 Esse entendimento fica muito claro com a leitura da obra O Federalista (1840), em que Alexander Hamilton, James Madison e John Jay, utilizam as lições de Montesquieu para fundamentar a separação dos poderes do governo republicano. Os autores partem do princípio de que a separação dos poderes (Legislativo, Executivo e Judiciário) é fundamental para o exercício da liberdade, pois, quando os poderes se concentram em um só lugar, subverte-se a liberdade. Apesar disso, a obra reconhece que esta separação não é absoluta e, na prática, o que se observou, especialmente nas Constituições dos Estados americanos, é que não há uma só em que os poderes estejam perfeitamente isolados uns dos outros. 
[...] Ao elaborar a forma como a federação norte-americana se constituiria, a Convenção de Filadélfia, em 1787, se deparou com a difícil tarefa de estabelecer um poder executivo forte o suficiente para cuidar dos problemas da nação - como resposta à crise da confederação entre os estados que até ali haviam sobrevivido - mas não tão forte que pudesse sufocar os outros poderes e as liberdades individuais [...] (CARVALHO e MAIA, 2019, p. 91).

As lições de Tocqueville (2005) descrevem o apreço norte-americano pelo princípio da soberania popular e como este se frutificou no terreno das 13 colônias inglesas:

[...] Na América, o princípio da soberania do povo não é oculto ou estéril, como em certas nações; ele é reconhecido pelos costumes, proclamado pelas leis; estende-se com liberdade e chega sem obstáculos às últimas consequências.

Se há um país no mundo em que se possa esperar apreciar por seu justo valor o dogma da soberania do povo, estuda-lo em sua aplicação aos assuntos da sociedade e julgar suas vantagens e seus perigos, esse país é seguramente a América [...]

Em nossos dias, o princípio da soberania do povo teve nos Estados Unidos todos os desenvolvimentos práticos que a imaginação é capaz de conceber. Ele se depurou de todas as ficções com que tomaram o cuidado de cercá-lo em outros países; vemo-lo revestir-se sucessivamente de todas as formas, conforme a necessidade do caso. Ora o povo em corpo faz as leis, como em Atenas; ora deputados, que o voto universal criou, o representam e agem em seu nome sob sua vigilância quase imediata [...] (TOCQUEVILLE, 2005, p. 66-67)

O presidencialismo também é apontado como um sistema puro de governo, cuja principal característica é o Poder Executivo unipessoal, desempenhado pela presidência de República. O Presidente da República acumula para si as funções de representante do Estado e Chefe de Governo e, para gerir o Poder Executivo, pondo em prática as funções que lhe competem, o presidente da República recebe o auxílio dos ministros de Estado, pessoas de sua confiança, as quais ele pode escolher, demitir ou substituir quando quiser, sem interferência do Poder Legislativo.

Diferente da forte relação de interdependência entre Executivo e Legislativo observada no parlamentarismo, um ponto marcante do presidencialismo é a independência recíproca que existe entre os referidos poderes: a investidura do presidente da República se dá pela escolha popular, por meio de votação direta ou indireta. A legitimação popular de que goza o presidente lhe confere o dever de zelar pela fiel execução das leis, assegurando a ele poderes inequívocos, a exemplo da discricionariedade na escolha das pessoas que irão compor o seu gabinete e o poder de veto.

No âmago da relação entre esses poderes, o presidente da República não pode interferir no mandato dos parlamentares nem dissolver a Câmara e vice-versa (FERREIRA FILHO, 2011). Nessa esteira, Carvalho e Maia (2019, p. 97) esclarecem que "[...] por não depender do Congresso para ser eleito, o Presidente goza de maior autonomia em face do poder legislativo, se comparado ao cargo de Primeiro Ministro Inglês [...]”.

Diferente do parlamentarismo, o Chefe de Governo presidencialista permanece no poder enquanto viger o seu mandato, não podendo perder o cargo apenas por falta de apoio 
do Legislativo. A destituição do presidente se dá por meio do processo de impeachment, decorrente da prática de crime de responsabilidade. Sobre isso, Carvalho e Maia (2019) explicam que, no presidencialismo norte-americano, o Poder Legislativo pode frear os poderes Executivo e Judiciário, através da gestão (control) da jurisprudência ou pelo processo de impeachment, procedimento que objetiva a punição da má conduta, tanto do Poder Executivo, quanto do Poder Judiciário.

[...] O sistema de "checks and balances" americano determina que a competência para iniciar o procedimento é da Câmara dos Representantes e a acusação deve versar sobre qualquer delito punível, de acordo com a legislação em vigor. Por outro lado, compete ao Senado proferir a sentença julgadora, na qual a condenação só se dá com a anuência de $2 / 3$ (dois terços) dos membros desta Casa, sob a presidência do Chief-Justice [...] (CARVALHO e MAIA, 2019, p. 101-102)

Na América Latina, conforme Pérez-Linãn (2000), o termo impeachment, também denominado "juicio político", 5 desde a década de 1990, tem sido uma forma de demonstração da democratização.

A propagação do uso desse mecanismo constitucional em solo latino-americano transcorreu para solucionar crises presidenciais que, por tradição, resultavam em intervenção militar. A utilização desse instrumento, permitiu que as democracias latino-americanas dissolvessem governos vigentes, mas sem a romper com o regime presidencialista (PÉREZ-LIÑAN, 2000).

Contudo, nada impede um presidente de adotar uma política inapropriada que venha causar sérios danos ao Estado, sem efetivamente praticar ato delituoso, e ainda assim manter-se no cargo. Em razão de não possuir responsabilidade política efetiva, como ocorre no parlamentarismo, o presidente pode perfeitamente agir contrariamente à vontade do povo, não existindo meios formais para retirá-lo da função (DALLARI, 2012).

O exercício da presidência da República segue por tempo determinado. Uma vez escolhido de maneira democrática, o presidente exerce seu mandato pelo prazo fixado previamente. Buscando evitar o retrocesso à forma de governo monárquico, estabeleceu-se a fixação de um período de governo e, após o seu término, os cidadãos são chamados novamente para votar e escolher um novo candidato para assumir o posto de presidente da República.

No início da instituição do sistema presidencialista norte-americano, não houve menção quanto à proibição de reeleição presidencial para períodos imediatos. Em face da omissão constitucional, observou-se o risco dessa lacuna possibilitar um governo vitalício, quiçá hereditário, criando-se a prática de permitir a eleição de até dois períodos consecutivos para o exercício do cargo de presidente da República. Essa premissa foi respeitada no Estado norte-americano até o presidente Franklin Roosevelt ser eleito para o terceiro mandato consecutivo, por ocasião da guerra. Como reação, em 1951, foi aprovada a emenda

5 Por "juicio político" entiendo ampliamente todo proceso legal por el cual el Congreso delibera para remover al presidente de su cargo. En América Latina existen tres modelos constitucionales de juicio político: el esquema legislativo - esencialmente tomado de la Constitución estadounidense - en donde el Congreso remueve al presidente sin depender de otras instituciones; el esquema judicial, en donde el Congreso autoriza una acusación que es evaluada por el poder judicial, y el sistema mixto, que combina elementos de ambas tradiciones (PÉREZ-LIÑAN, 2000, p. 68). 
constitucional que estipulou o máximo de dois mandatos eletivos consecutivos de governo presidencial.

[...] Sobre a reeleição, grandes Presidentes como George Washington e Thomas Jefferson - mesmo com toda expectativa nacional - ao fim de seus segundos mandados, decidiram se retirar do cargo de Presidente, mesmo com a possibilidade de lá permanecerem, dado o silêncio constitucional. Ambos alegaram o perigo da ocupação da cadeira de Presidente por um longo período, sob pena de tornar tal função vitalícia.

Disso tudo restou um precedente e a forte tradição popular de que o Presidente dos Estados Unidos só pode se reeleger uma única vez. Apesar de Franklin Delano Roosevelt ter exercido por quatro períodos consecutivos o mencionado cargo, após a sua morte, foi aprovada a Emenda XXII, que estabeleceu que o cargo de chefe do poder norte-americano só pode ser ocupado pela mesma pessoa por dois mandatos [...] (CARVALHO e MAIA, 2019, p. 96-97).

Para além dos Estados Unidos da América, o sistema presidencialista se propagou por diversos lugares ganhando bastante notoriedade entre os países latino-americanos. Segundo Nohlen (2013, p. 8), na América Latina, o presidencialismo é o sistema político preferido pós-redemocratização, embora seja apontado como o responsável pelo colapso das democracias latino-americanas:

[...] En el transcurso de la redemocratización de los sistemas políticos de América Latina en los años 1980, se volvieron a reactivar en todos lados sistemas presidenciales, aunque en algunos países se han mostrado debilidades funcionales de presidencialismo en la época preautoritaria, y se han discutido vivamente alternativas de reforma. Se ha sostenido incluso que el derrumbe de las democracias en los años 1960 y 1970 tuvo su principal causa en el presidencialismo. Por lo tanto se han recomendado urgentemente a los países latinomaericanos tras la democratización substituir el presidencialismo por el parlamentarismo $[\ldots]$.

Nohlen (2013) destaca que a experiência parlamentarista na América Latina é quase desconhecida. No entanto, os escassos casos latino-americanos podem ser encarados como negativos, a exemplo do Chile, durante os anos de 1891 a 1925, cujo parlamentarismo se deu "às avessas", com grande instabilidade governativa no país, oligarquização da política e censura apenas dos ministros, mas não do Chefe de Governo.

As posições a favor do parlamentarismo na América-latina e as condições político-institucionais para implementá-lo são inexpressivas, o que reduz as chances de se realizar uma reforma de tamanha envergadura no sistema de governo. Nohlen (2013) lembra que, no Brasil, a possibilidade de instauração do parlamentarismo foi rejeitada no plebiscito de 1993, quando o presidencialismo foi escolhido.

Depreende-se que, apesar da experiência dos Estados Unidos da América ter sido o protótipo do sistema presidencialista, à medida que o presidencialismo foi instituído em outros países, ganhou contornos condizentes com a realidade histórica, política e social de cada nação que o adotou. Diante disso, não se pode falar em um modelo ideal de presiden- 
cialismo, mas apenas na existência desse versátil sistema de governo, que se amolda ao contexto em que é reproduzido.

\section{1 - O presidencialismo brasileiro}

O Brasil seguiu a tradição latino-americana e optou pelo sistema presidencialista. Em 1889, superado o período imperial e atingida a República no Brasil, devia-se escolher um tipo de governo para a nação brasileira: parlamentarismo ou presidencialismo. Naquele momento, o país se encontrava em um Governo Provisório, em plena ditadura e, qualquer regime legal que fosse instituído para aquela ocasião, deveria ser liberal, pouco importando qual seria o resultado da escolha.

Assim, o presidencialismo foi escolhido, ancorado apenas na certeza de que não se desejava o retorno à monarquia. Medeiros e Albuquerque (1932) consignam que não houve discussão sobre o tema e a população foi surpreendida pela novidade. Nas palavras de Bonavides (2001, p. 412), “[...] acordamos no presidencialismo da mesma maneira que amanhecemos na República... Em ambos os casos, as instituições do País foram marteladas pela surpresa $[\ldots]^{\prime \prime}$.

[...] O regime presidencial não suscitou nenhum debate geral. Ele apareceu, um dia, em um projeto de constituição decretado pelo Governo Provisório. Ninguém o discutiu. Foi aceito, por assim dizer, em silêncio.

A propaganda republicana se tinha feito sobre uma base, que se pode chamar de "negativa". O que se queria era destruir o regime monarquista.

Essa é aliás a regra em todas as propagandas revolucionárias; o acordo se faz apenas acerca de um ponto: a necessidade de suprimir o que há. Quanto ao que convém pôr no lugar, as opiniões divergem [...] (MEDEIROS E ALBUQUERQUE, 1932, p. 15-16).

A escolha do presidencialismo, segundo Medeiros e Albuquerque (1932), decorreu da ignorância de grande parte dos membros da Assembleia Constituinte e da influência dos Estados Unidos da América, pois, parte dos integrantes da Constituinte de 1891 era de "calouros", ou seja, pessoas sem experiência na vida pública, com pouca ou nenhuma educação política. Uma parte dessas pessoas era formada por jovens oficiais vindos de quartéis, enquanto a outra era composta por um pequeno grupo de positivistas, considerados realmente ativos e que influenciaram demasiadamente na tomada de decisão. Existiam ainda poucos políticos da época do império, contrários ao presidencialismo, mas que não ousavam se opor, devido à falta de conhecimentos sobre o sistema que se desejava implantar.

[...] no Brasil o regime presidencial nasceu da influência norte-americana e não sob a pressão de fatos políticos ou de condições existentes. Já a nossa unidade tinha sido realizada pelo Império e as instituições parlamentares estavam em prática, operando a evolução política brasileira para a democracia. A república, portanto, não devia ter interrompido a tradição parlamentar [...]. Por certo, os Estados Unidos da América serviu de espelho para a adoção do presidencialismo em variados países, já que, no fim das contas foi ele quem principiou esse modelo de governo. No Brasil, essa influência se ligaria à justificativa de que o presidencialismo era sinônimo de prosperidade nas poucas vezes que se ouvia 
ou lia a seu respeito em discursos, artigos ou conversas. Presumia-se que se ele havia levado grande prosperidade ao Estado americano o mesmo haveria de se cumprir em terras brasileiras (MAGALHÃES apud MEDEIROS E ALBURQUERQUE, 1932, p. 616).

Tinha-se a fantasia de que se o Brasil optasse pelo presidencialismo seria ungido pela mesma prosperidade norte-americana. Medeiros e Albuquerque (1932) sustentam que esse entendimento é um sofisma, pois desconsidera outros fatores alheios ao presidencialismo norte-americano que corroboraram para o sucesso da referida nação. Sob esse raciocínio tem-se que, independentemente do sistema de governo escolhido pelos pais fundadores, os Estados Unidos da América chegariam ao sucesso, já que esse resultado envolve questões que vão muito mais além do sistema de governo. Após tantos anos, a falácia só se confirma: inobstante compartilhar do mesmo sistema de governo dos Estados Unidos, o Brasil nunca alcançou o patamar da potência norte-americana.

[...] Pelo fato de uma nação estar mais adiantada dez anos depois de ter subido ao poder um certo governo, não quer dizer que o progresso tenha sido promovido por esse governo. O mundo não pára. Mesmo os governos mais retrógrados e nefastos não têm impedido o progresso de certas nações.

Se fosse possível preceder experimentalmente e lidar com uma grande nação como se lida com um animal de laboratório, seria necessário submetê-la a um certo regime, notar os resultados obtidos, repô-la no estado anterior e recomeçar a experiência com outro regime, para então comparar o que se tivesse obtido com um e com outro. Mas isso não se pode fazer. Não há remédio senão recorrer a induções e deduções diversas: imaginar o que se poderia passar nesta ou naquela hipótese [...] (MEDEIROS E ALBUQUERQUE, 1932, p. 28-29).

Desde a República, o Brasil segue com o presidencialismo de forma quase ininterrupta. A exceção se deu em 1961, com a renúncia do então presidente Jânio Quadros e a relutância de setores da sociedade em aceitar no poder o seu sucessor natural: João Goulart. Instituiu-se o parlamentarismo por meio da Emenda Constitucional n ${ }^{\circ} .4$, de 2 de setembro de 1961, mas esse sistema não vigorou por muito tempo, sendo rejeitado por meio de plebiscito. A Emenda Constitucional n ${ }^{\circ}$. 6, de 1963, então revogou o parlamentarismo e reestabeleceu o presidencialismo, que permanece até hoje como o sistema de governo do país, nos termos da Constituição Federal de 1988.

Nos últimos anos, a crise política no Brasil reacendeu a temática do parlamentarismo. $\mathrm{Na}$ imprensa, as manchetes variam de "Parlamentarismo ressuscita e volta à gaveta em uma semana" (GAZETA DO POVO, 05/06/2018); "Em meio à crise, políticos articulam parlamentarismo a prazo" (O GLOBO, 16/08/2017) a "Nas entrelinhas: A volta do parlamentarismo" (CORREIO BRAZILIENSE, 15/08/2017). Retomando as características e funcionamento do presidencialismo, Barcellos (2018) especifica que, do ponto de vista teórico, o sistema presidencialista está estruturado em três eixos: a) especialização funcional entre os poderes; b) independência orgânica e c) controles recíprocos.

Por especialização funcional compreende-se que cada poder - Executivo, Legislativo e Judiciário - é possuidor de competências privativas, constitucionalmente previstas, a serem realizadas sem interferências externas, salvo aquelas autorizadas pela Constituição. 
Em regra, o Legislativo edita as normas gerais, o Executivo as executa de ofício, enquanto o Judiciário julga os conflitos resultantes dessas atividades.

A independência orgânica impede que uma pessoa seja membro, ao mesmo tempo, de mais de um poder, assim como proíbe que um poder destitua membros que integram outros poderes, meramente por questões de ordem política.

Os controles recíprocos que existem entre os poderes têm por finalidade evitar que um se sobreponha ao outro, ultrapassando a sua esfera de competência, razão pela qual a Constituição Federal elenca as hipóteses de controles recíprocos.

Concretamente, para além das competências privativas de cada poder usufruídas de forma absoluta, a Constituição de 1988 prevê as circunstâncias em que os poderes desempenharão funções atípicas, ou seja, o Legislativo irá administrar e julgar, o Judiciário administrar e legislar, bem como, o Executivo legislar e julgar.

Cabe ainda destacar a relação de interpenetração dos poderes, especificamente em relação ao Poder Executivo, cujo chefe atua de forma fundamental no processo legislativo, a partir de prerrogativas como: iniciar o processo legislativo em relação a um conjunto considerável de matérias, ${ }^{6}$ adotar em casos de relevância e urgência as medidas provisórias ${ }^{7}$ e o poder de veto. ${ }^{8} \mathrm{O}$ panorama de ampla outorga de poderes ao presidente da República determinado pela Constituição Federal de 1988 é alvo de uma série de críticas ao desequilíbrio entre os poderes. Nesse passo, segue-se na evolução do estudo e exame dos principais fundamentos do presidencialismo na realidade brasileira.

\section{3 - Federalismo}

De acordo com Baracho (1995, p. 50), federalismo é uma forma de descentralização do poder, que proporciona uma aproximação entre a autoridade política e os cidadãos; enquanto que a federação é o meio de aplicação do federalismo, que tem por objetivo "incorporar as unidades autônomas ao exercício de um governo central, sob bases constitucionais rigorosas", assentadas em três grandes princípios: "o princípio da separação, o princípio da autonomia e o princípio da participação".

No âmbito brasileiro, o princípio federativo nasceu com a Primeira República, em 1889, e se consolidou na Constituição de 1891, sob a inspiração dos Estados Unidos da América, inaugurado em 1787, durante a Convenção da Filadélfia, onde as treze ex-colônias inglesas se reuniram e acordaram formar um novo Estado soberano, a partir da disposição parcial de suas soberanias.

[...] Os pais fundadores ("founding fathers"), ou autores constitucionais, na nomenclatura de Dahl (2015), buscaram definir um modelo que prosperasse diante das deficiências e instabilidades da confederação, sem resgatar as antigas formulações da metrópole inglesa, liderando, pois, o fortalecimento de uma sistemática na qual coexistisse um governo central com a autonomia local e,

\footnotetext{
$\mathrm{CF} / 88$, artigo 61 .

$\mathrm{CF} / 88$, artigo 62 .

$\mathrm{CF} / 88$, artigo 66 .
} 
para além disto, que se contivesse e se orientasse segundo a vontade do povo americano.

Assim, a Carta escrita de 1787 emergia como o marco de um novo conceito para o termo "República", conciliada a autoridade e independência nacional com a autonomia e autogoverno de unidades políticas locais.

Já no que tange ao elo entre a composição republicana federalista e os postulados de um regime democrático, nota-se que os discursos desde a composição ao amadurecimento da nação americana demonstram a crença na vinculação do poder à anuência do povo e na garantia e reconhecimento de direitos inerentes à essência humana. O próprio respaldo à ordem constitucional deriva de uma forte crença ou assentimento de que as disposições em sua Carta Maior são sensíveis aos seus direitos e deveres como cidadãos americanos [...] (REIS, 2019, p. 15-16).

Apesar da inspiração norte-americana, não se pode dizer que o federalismo se desenvolveu em terras brasileiras com a mesma pujança dos Estados Unidos. Bastos (2010) explica que, enquanto nos Estados Unidos houve um esforço conjunto das treze ex-colônias que, então independentes, decidiram formar um único Estado descentralizado, no Brasil ocorreu o inverso. Na época do Império, sob a vigência da Constituição de 1824, o Brasil era um Estado unitário, cujo poder político se centralizava em apenas um ente governamental. Com o advento da República, o Brasil se descentralizou e constituiu unidades autônomas (províncias). ${ }^{9}$

A Constituição brasileira de 1891 foi a primeira a assentar o princípio federativo. Souza (2005) assinala que nesse período a federação brasileira funcionou de maneira isolada, pois havia uma concentração de recursos públicos destinada a poucos Estados-membros, além disso, as relações existentes entre os entes federativos eram escassas. Segundo Ramos (2012), a forma como o princípio federativo se materializou, nessa época, foi prejudicial para a maioria dos Estados, principalmente para os que integravam o nordeste do país: eles não detinham os recursos suficientes para manter a administração pública e ofertar os serviços necessários à população. ${ }^{10}$ Em face da desigualdade latente entre os Estados-membros da federação, era impossível cumprir o preceito constitucional ${ }^{11}$ de que cada um era responsável por prover as necessidades do seu governo.

O movimento revolucionário de 1930, os choques entre as oligarquias estaduais e a forte crise econômica conduziram à queda do regime constitucional de 1891, oportunidade em que Getúlio Vargas assumiu o Governo Provisório, nomeando interventores para os Estados (BERCOVICI, 2004), o que claramente os privou de efetiva autonomia (BASTOS, 2010).

A Constituição de 1934 manteve a forma federativa de Estado e, consoante Souza (2005), aumentou as relações intergovernamentais por meio da autorização para que o go-

9 Celina Souza (2005) lembra que a federação se formou a partir das províncias já existentes no país durante a época imperial, possuidoras de poderes administrativos, mas sem autonomia política, seja formal ou informal.

10 “[...] com a proposta de um federalismo simétrico em uma realidade muito heterogênea, o sistema funcionou de modo precário, pois a assimetria real exigia socorro permanente do poder central requerido pelos Estados-membros pobres, o que gerou uma grande distorção no federalismo recém-implantado [...]" (RAMOS, 2012, p. 29).

11 Artigo $5^{\circ}$. - Incumbe a cada Estado prover, a expensas próprias, as necessidades de seu Governo e administração; a União, porém, prestará socorros ao Estado que, em caso de calamidade pública, os solicitar (BRASIL, 1891). 
verno federal cedesse às instâncias subnacionais recursos e também assistência técnica. Além disso, assegurou aos municípios recursos próprios, a serem coletados por eles, como também parcelas de um imposto estadual. Ainda, a Carta Constitucional corporificou no artigo 10 as competências concorrentes entre a União e os Estados. No entanto, essa Constituição não vigorou por muito tempo, dado o golpe de Estado de 1937, liderado por Vargas.

Instaurado o Estado Novo, o governo decretou a intervenção federal em todos os Estados, designando-lhes interventores responsáveis pela interligação entre os Estados, Ministérios e o presidente da República. Para manter-se como interventor, era necessário contar com a confiança total de Getúlio Vargas. Durante esse período, criou-se o Departamento Administrativo do Serviço Público - DASP, órgão responsável por controlar todo o sistema administrativo do país, o que lhe incumbia da elaboração do orçamento anual, seu controle e execução (BERCOVICI, 2004). O momento vivenciado era, portanto, antidemocrático, já que o poder se concentrava em Getúlio Vargas, o que, significava o retorno à forma unitária de Estado.

Restituída a democracia no país, a Constituição de 1946 consolidou o que Bercovici (2004, p. 42-43) denomina de "federalismo cooperativo". ${ }^{12}$ Ganharam destaque discussões sobre a "Questão Regional" e as chamadas "regiões-problema", em que se inseriam o Nordeste e a Amazônia. Criou-se a SUDENE, cuja função era "[...] dinamizar a força produtiva das suas áreas de atuação e integrá-las ao sistema nacional [...]” (BERCOVICI, 2004, p. 43). Todo esse esforço, entretanto, foi interrompido pelas fortes crises econômicas iniciadas na década de 60 e que foram seguidas do golpe de 1964.

$\mathrm{O}$ regime autoritário no Brasil atrelou a imagem do federalismo à ideia de ditadura e concentração de poder. Foi um período pautado na política do "federalismo de integração", ${ }^{13}$ elaborado por Alfredo Buzaid, que sob o pretexto da integração nacional, eliminou a autonomia dos Estados-membros e concentrou todos os poderes na União.

Findo o governo ditatorial no Brasil, iniciou-se a redemocratização e muitas expectativas foram criadas sobre o federalismo na nova ordem constitucional. A atual Constituição brasileira, em seu artigo primeiro, firma o Brasil como uma República Federativa, integrada pela união dos Estados, municípios e do Distrito Federal, circunstância que não é passível de deliberação, nem por emenda constitucional (art. 60, $§ 4^{\circ}$., I)

12 Prática já iniciada em 1934, que objetivava a redução dos desequilíbrios regionais, favorecendo "a cooperação e a integração nacional".

13 “[...] Com os militares, o Governo Central passou a enfeixar uma série de poderes e atribuições ocasionando forte centralização na esfera da União. O federalismo, praticamente, desapareceu neste período, apesar de nominalmente estar previsto nas Cartas outorgadas de 1967 e 1969. Como forma de matizar a total falta de autonomia dos entes federados, criaram-se eufemismos como o "federalismo de integração". (...) Sob o pretexto da "integração nacional", todos os instrumentos de promoção do desenvolvimento econômico deveriam ser centralizados na União. Para Buzaid, o "federalismo de integração" iria além do federalismo cooperativo, atribuindo à União os poderes necessários para dirigir a política nacional, evitar conflitos com as unidades federadas e promover o desenvolvimento econômico com o máximo de segurança coletiva. Realmente, o "federalismo de integração" foi tão além do federalismo cooperativo que praticamente extinguiu o sistema federativo brasileiro, sempre com a justificativa da "segurança nacional" [...]" (BERCOVICI, 2004, p. 50-51). 
Nas palavras de Celso Bastos (2010, p. 415), federação é "[...] a forma mais sofisticada de se organizar o poder dentro de um Estado [...]”. É, portanto, a distribuição do poder do Estado entre os entes políticos que o compõem, preservando-lhes a autonomia. Geralmente, a divisão de poder se dá entre a União e os Estados-membros, por meio de um vínculo associativo indissolúvel, conforme se observa na determinação constitucional de 1988. Nesse sentido, na composição da federação coexistem o poder central e o poder regional, cada um atuando em esferas específicas de competência, submetendo os cidadãos a essas duas esferas de poder.

O texto constitucional 1988 tomou para o Brasil o modelo de federalismo simétrico, ignorando a assimetria da realidade. Souza (2005, p. 111) entende que as competências, os recursos e políticas públicas dos entes subnacionais estão tão detalhados no texto constitucional, que resta pouca margem para a promoção de iniciativas específicas. Da mesma forma, as decisões do Supremo Tribunal Federal firmam que as constituições e leis estaduais devem refletir o texto constitucional federal, levando os Estados a serem quase que "entes gestores do Direito federal".

As competências da União previstas nos artigos 21 e 22 da Constituição Federal são bastante amplas e específicas, cabendo aos Estados-membros competências residuais que, dado o alto nível de rigidez constitucional, pouco espaço se tem para o exercício dessas competências (SOUZA, 2005). Além disso, a concentração de atribuições e recursos na União a fortaleceu e deixou os entes federados como reféns:

[...] Não se pode dizer, mesmo diante da complexidade do sistema, que o federalismo brasileiro seja descentralizado. O certo é que possui um viés de descentralização, contudo enfrenta sérias dificuldades em virtude das grandes disparidades de riqueza entre os entes federados, o que torna muitos deles dependentes das transferências de recursos da União, mesmo que estes sejam compulsórios e estejam previstos na Constituição. Isso fragiliza os Estados-membros e mantém a União em uma situação de superioridade, mesmo tendo desejado a Constituição construir uma outra realidade [...] (RAMOS, 2012, p. 42).

De fato, existem competências comuns ${ }^{14}$ aos entes federativos, assim como competências concorrentes ${ }^{15}$ entre eles. Bercovici (2004) afirma que as competências comuns ${ }^{16}$ são responsáveis pelo "federalismo cooperativo", no Brasil: nem a União nem outro ente federado pode atuar de forma isolada, devendo todos atuarem de modo conjunto, colaborando ${ }^{17}$ uns com os outros, nos termos definidos na Constituição.

${ }_{14} \mathrm{CF} / 88$, artigo 23 .

$15 \mathrm{CF} / 88$, artigo 24.

16 Deve-se salientar que no rol de competências comuns se inserem relevantes direitos sociais a serem promovidos. A estipulação por esse tipo de competência é louvável quando se pensa que toda a federação - União, Estados, Municípios e Distrito Federal - diligenciará para a promoção e garantias desses direitos. Entretanto, é uma proposição a ser vista sempre com muita cautela, vez que quando se delega uma mesma atribuição para muitos componentes, sem estabelecer os mecanismos reais para o funcionamento, tem grandes chances de o objetivo não ser alcançado de forma efetiva.

17 Essa cooperação parte do pressuposto da interdependência existente entre várias matérias que são de interesse comum, tornando dificultoso atribuí-las a apenas determinado ente. 
Esse tipo de federalismo também é denominado na doutrina de "intergovernamentalização". Através dele, busca-se a cooperação intergovernamental a fim de atender os objetivos comuns da sociedade no que tange às questões sociais, econômicas e culturais, e a participação dos entes federativos se dá mediante programas e financiamentos conjuntos (BARACHO, 1995).

De acordo com Baracho (1995, p. 53), essa espécie de federalismo "responde às mutações do mundo contemporâneo, sem alterar a repartição constitucional de competências legislativas e às fontes de financiamento".

Em sentido contrário, Souza (2005) entende que o federalismo cooperativo é algo de difícil concretização, devido às diferentes capacidades dos governos subnacionais de implementarem políticas públicas, decorrentes das enormes desigualdades financeiras, técnicas e de gestão existentes e pela ausência de mecanismos constitucionais ou institucionais que estimulem a cooperação, o que deixa o sistema extremamente competitivo.

Elencadas as principais peculiaridades e posições doutrinárias sobre o federalismo desenvolvido em solo brasileiro, passa-se ao estudo de outro importante fundamento do presidencialismo no Brasil: o sistema eleitoral proporcional de lista aberta.

\section{4 - Sistema ELEITORAL PROPORCIONAL DE LISTA ABERTA}

O sistema eleitoral de um país democrático define como serão escolhidos os representantes do povo. Numa acepção mais precisa, o sistema eleitoral é "[...] o conjunto de regras que define como, em uma determinada eleição, o eleitor pode fazer suas escolhas e como os votos são contabilizados para serem transformados em mandatos [...]" (NICOLAU, 2004, p. 10).

O Brasil adota os sistemas eleitorais majoritário e proporcional para a escolha dos representantes políticos da nação, quais sejam presidente da República, governador de Estado, senador e prefeito, com base na maioria dos votos, o que o torna um modelo mais simples para a compreensão pelo eleitor. O presente artigo limitar-se-á a analisar o sistema eleitoral proporcional em lista aberta, utilizado para a escolha dos representantes do Poder Legislativo nas esferas federal, estadual e municipal.

Sobre o sistema proporcional, Raquel Machado (2018) destaca a sua complexidade oriunda dos sucessivos cálculos necessários à obtenção do resultado da eleição. O Código Eleitoral brasileiro, em seu artigo 84, determina que a escolha dos membros da Câmara dos Deputados, das Assembleias Legislativas e Câmaras Municipais se dará por meio da representação proporcional, relação entre os votos obtidos e o número de cadeiras a ser preenchido em cada Casa Legislativa. Machado (2018) defende que o sistema proporcional ${ }^{18}$ permite maior participação dos grupos minoritários no Poder Legislativo, sendo fator de otimização do princípio democrático e de valorização das múltiplas correntes ideológicas.

Do sistema proporcional, surgem duas variantes: o voto único intransferível e o sistema de lista (NICOLAU, 2004). O Brasil adota o sistema de lista, que se preocupa, primei-

18 Vários são os países que se utilizam do sistema eleitoral proporcional, como a Bélgica, Dinamarca, Noruega, Portugal, Espanha, Argentina, Chile, Brasil, África do Sul e outros. 
ramente, em distribuir entre os partidos as cadeiras que serão ocupadas no Legislativo e, posteriormente, em realizar essa distribuição entre os candidatos mais votados.

No Brasil, a representação proporcional foi introduzida no Código Eleitoral de 1932 e a Constituição de 1934 foi a primeira a prevê-la, sofrendo algumas modificações ao longo do tempo, até ganhar o formato atual (CAMARÃO, 2012). Para Nicolau (2004), o sistema de lista é simples, pois, 1) cada partido ou coligação apresenta uma lista de candidatos; 2) após a eleição, faz-se a contagem dos votos que cada lista partidária recebeu; 3 ) passa-se à distribuição das cadeiras entre os partidos, de forma proporcional aos votos obtidos pelas listas e 4) as cadeiras são ocupadas por alguns dos nomes que compõem essas listas. No entanto, o autor destaca que na prática ${ }^{19}$ o sistema de lista se torna complexo em virtude de aspectos como: a) a fórmula eleitoral utilizada na distribuição das cadeiras; b) o tamanho dos distritos e os níveis para a alocação de cadeiras; c) a cláusula de exclusão; d) a previsão de coligações partidárias e e) as regras para a escolha dos candidatos da lista, de modo que os quatro primeiros aspectos definem o percentual/número de cadeiras que cada partido obterá.

Superada a divisão de cadeiras entre os partidos, é preciso determinar quem as ocupará. Para isso, existem as listas utilizadas como critério, que podem ser abertas, fechadas, flexíveis e livres.

O sistema de lista aberta ${ }^{20}$ é utilizado em um contingente reduzido de países como Brasil, Finlândia, Polônia e Chile. Nesse modelo, cabe aos eleitores definir quem são os candidatos que ocuparão as cadeiras das casas legislativas conquistadas pelo partido ou pelas coligações. Assim, cada partido apresenta uma lista de candidatos, sem ordem predeterminada, e o eleitor vota em um dos nomes indicados. O número de votos obtidos pelos candidatos da lista será contabilizado para definir a quantidade de cadeiras que o partido terá direito e essas cadeiras serão ocupadas pelos candidatos que obtiverem mais votos. No Brasil, o sistema de lista aberta permite que o eleitor vote tanto no candidato que está concorrendo por qualquer partido, quanto votar somente no partido, o chamado voto de legenda (NICOLAU, 2004).

19 Ainda segundo as lições Nicolau, 2004, tem-se que a fórmula eleitoral é o cálculo utilizado para dividir as cadeiras pertencentes a cada distrito entre os partidos por meio de médias ou quotas; a magnitude do distrito significa que quanto maior o distrito eleitoral tanto maior será o número de cadeiras e, com efeito, mais partidos têm a chance de eleger representantes e, inversamente, quanto menor o distrito eleitoral, também tanto menor será a chance de um partido pequeno conseguir angariar uma vaga; a cláusula de exclusão, também conhecida como cláusula de barreira, estipula que um partido somente terá direito de obter representação caso atinja um número $\mathrm{x}$ de votos. Por um viés, essa cláusula dificulta o ingresso dos pequenos partidos no âmbito do Poder Legislativo e impede a ampla fragmentação partidária, garantindo ao governo governabilidade; nas coligações eleitorais os partidos se unem para disputar as eleições, preservando suas autonomias, bem como, ofertando sua própria lista de candidatos, no entanto, no processo de apuração têm os votos agregados para efeito do cálculo das cadeiras.

20 Em oposição à lista aberta existe o sistema de lista fechada que, segundo Nicolau (2004), é o tipo mais usado em países como Argentina, Portugal, Bulgária, Espanha, Turquia, Uruguai, Colômbia, Paraguai, Costa Rica e África do Sul. Nesse modelo, antes das eleições, os partidos políticos estabelecem a ordem que aparecerão seus candidatos na lista. O eleitor, por sua vez, vota no partido e as cadeiras por ele conquistadas serão ocupadas pelos candidatos na ordem definida previamente. Não há aqui espaço para o eleitor manifestar sua preferência por um candidato específico, o que demonstra ser uma desvantagem para a realidade de algumas democracias. Para o contexto brasileiro, essa sistemática se mostra inviável, considerando a fragilidade dos partidos e a ausência de ideologia consolidada, isso porque, em geral, o eleitor brasileiro manifesta sua vontade política por identificação com o candidato político, e não com o partido. 
Sobre esse modelo de representação proporcional, Felipe Camarão (2012) aponta como vantagens: a justiça desse sistema, pois nele os votos têm o mesmo valor; representação de minorias e o dinamismo que contribui para pluralismo político, possibilitando que correntes ideológicas distintas estejam presentes no Parlamento. Em contrapartida, o autor aponta como desvantagens: a fraqueza e a instabilidade dos governos que o pluralismo partidário pode provocar, em virtude das fusões partidárias oportunistas, que incutem no eleitorado insegurança e desconfiança; a complexidade das técnicas de contagem de votos e da distribuição de cadeiras nas Casas Legislativas, que são desconhecidos pelos eleitores, e que também despertam nos cidadãos a incerteza quanto aos resultados e ao procedimento de distribuição das cadeiras que podem fazer que um candidato que angarie um número elevado de votos, eleja outros candidatos do seu partido, que tenham recebido votação inexpressiva.

Raquel Machado (2018) entende que o sistema proporcional é um modelo que subtrai do eleitor o conhecimento sobre o destino do seu voto, pois, na sociedade brasileira, o eleitor tem maior identificação com o candidato do que com os partidos políticos. Essa característica pode provocar distorções acerca da legitimidade do processo eleitoral ou até mesmo perplexidades, em que candidatos com poucos votos ou nenhum conseguem ser eleitos. A crítica da autora é certeira, quando se analisa a história das eleições no país e se constata que, no Brasil, o sistema proporcional de lista aberta trouxe para o cenário nacional alguns casos de grande publicidade, que revelaram as mais patentes falhas estruturais desse modelo.

Exemplificando, nas eleições de gerais de 2002, o candidato a deputado federal Enéas Carneiro, integrante do pequeno partido político PRONA, conquistou o total de 1.573 .6428 (um milhão quinhentos e setenta e três mil seiscentos e quarenta e dois) votos, sendo eleito para a Câmara dos Deputados pelo Estado de São Paulo. Com a quantidade de votos obtida para o seu partido, Enéas Carneiro conseguiu eleger mais cinco deputados federais, que não teriam a mínima chance de alcançar uma cadeira dada a inexpressiva votação que tiveram. A distorção restou constatada nos dados da eleição, quando se verificou que, dos cinco candidatos "puxados" pela grande votação de Enéas Carneiro, quatro sequer ultrapassaram o total de mil votos para um Estado como São Paulo, detentor da maior população do país. $\mathrm{Na}$ ordem, segue a quantidade de votos por candidato: Enéas Carneiro (1.573.642); Amauri Gasques (18.421); Irapuan Teixeira (673), Elimar Damasceno (484); Ildeu de Araujo (382) e Vanderlei de Souza (275). ${ }^{21}$

Situação semelhante se deu nas eleições de 2010, quando o humorista Tiririca, também candidato federal por São Paulo, angariou o total de 1.353.820 (um milhão trezentos e cinquenta e três mil oitocentos e vinte) votos conquistando sua cadeira na Câmara federal e mais três para o seu partido. ${ }^{22}$

Por óbvio, tais ocorrências demonstraram a necessidade de se rever o modelo de proporcionalidade em lista aberta. Como candidatos com tão pouca representatividade poderiam ser eleitos, enquanto tantos outros bem mais votados não? Essa é, no mínimo, uma circunstância embaraçosa para muitos eleitores. Alguns partidos políticos, para terem re-

21 Tribunal Superior Eleitoral. In: http://www.tse.jus.br/eleicoes/eleicoes-anteriores/eleicoes-2002/candidaturas-votacao-e-resultados/resultado-da-eleicao-2002. Acesso em: 21 abr. 2019.

22 Tribunal Superior Eleitoral. In: http:/www.tse.jus.br/eleicoes/eleicoes-anteriores/eleicoes-2010/ candidaturas-votacao-e-resultados/estatisticas. Acesso em: 21 abr. 2019. 
presentação nas casas legislativas, utilizam-se dos "puxadores de votos" - artistas/celebridades e políticos com grande poder apelativo - para ajudar os candidatos menos votados.

Quanto a esse aspecto, a Lei $n^{\circ}$. 13.165/2015 promoveu algumas alterações no Código Eleitoral, entre as quais está evitar que candidatos que obtenham um número ínfimo de votos se elejam, estabelecendo que serão aptos para serem eleitos os concorrentes que alcançarem votos igual ou superior a $10 \%$ do quociente eleitoral (número de votos válidos em cada circunscrição, dividido pelo número de cadeiras a ser preenchido). ${ }^{23}$

Apesar das imperfeições mencionadas, após um estudo sobre os sistemas eleitorais em vários países do mundo, Nicolau (2004) constatou que os sistemas proporcionais são realmente os mais generosos em termos de representatividade, como também produzem uma fragmentação partidária maior. Assim, há pouca probabilidade de o partido mais votado conseguir compor maioria absoluta do legislativo, fragmentariedade que certamente afeta a governabilidade.

Como se vê, do ponto de vista da representatividade, o sistema proporcional é positivo por oportunizar o englobamento dos interesses majoritários e minoritários por meio da diversidade de opiniões dos partidos políticos no centro das casas legislativas. Por sua vez, esse sistema também possibilita o ingresso de muitos partidos políticos oportunistas, sem nenhuma ideologia, aproveitadores da configuração do sistema eleitoral de lista aberta. As referidas vantagens e desvantagens do sistema proporcional sempre devem ser avaliadas considerando a ausência de educação política de grande parte da população que, literalmente, não sabe votar. ${ }^{24}$

A seguir, o último fundamento que este trabalho julga importante para a melhor compreensão do presidencialismo no Brasil.

\section{5 - MUlTiPARTIDARISMO}

Kelsen (2012) defende que os partidos políticos são um dos elementos mais significativos de uma democracia real, pois, são órgãos de formação da vontade do Estado. Sem eles, isoladamente, o indivíduo não tem poder de exercer influência política concreta na construção dessa vontade. Assim, para que a democracia possa existir, é preciso que os indivíduos se agrupem conforme suas semelhanças políticas para liderar a vontade geral e alcançar os seus fins políticos.

A conceituação de partido político aparece na doutrina pátria de formas variadas. Para Silva (2006, p. 395), o partido político é “[...] uma forma de agremiação de um grupo social que se propõe organizar, coordenar e instrumentar a vontade popular com o fim de assumir o poder para realizar seu programa de governo [...]". Na percepção de Masson (2016, p. 422), eles são “[...] agrupamentos voluntários de indivíduos que comungam de semelhantes pontos de vista políticos e pretendem fazer prevalecer suas ideias para conquistar o poder, ou ao menos inspirar decisões políticas [...]”. Para o artigo $1^{\circ}$. da Lei nº 9.096/1995, “[...]

$23 \mathrm{Qe}=\mathrm{Vv} / \mathrm{n}^{\mathrm{o}}$. de cadeiras.

24 Não saber votar significa que a população brasileira não possui educação política, tampouco detém conhecimento sobre os sistemas eleitorais utilizados no Brasil. 
O partido político, pessoa jurídica de direito privado, destina-se a assegurar, no interesse do regime democrático, a autenticidade do sistema representativo e a defender os direitos fundamentais definidos na Constituição Federal [...]".

A existência dos partidos políticos é consequência do sistema representativo. A função política que os parlamentos começaram a desempenhar desde o seu nascedouro fez que surgissem os primeiros grupos ou facções do que hoje se conhece por partidos políticos. Embora esses partidos tenham sido alvo de muitas críticas nos séculos passados, quando se criou muita resistência a sua adoção, nas atuais democracias esse é um ponto que não mais se discute, pois o partido político é uma necessidade (BASTOS, 2010).

Genericamente, os partidos políticos estão inseridos em uma das formas de sistema partidário: monopartidarismo, bipartidarismo e pluripartidarismo. O monopartidarismo é a existência do partido único encontrado em Estados de ideologias marxistas ou ditaduras de direita de inspiração fascista (BASTOS, 2010) e contrário à essência da democracia e o ideal de liberdade, já que as minorias são excluídas quando se opõem às ideias dominantes. No bipartidarismo, há a predominância de dois partidos políticos na disputa do poder, prevalecendo o que for majoritário, a exemplo dos Estados Unidos da América e Inglaterra. No sistema multipartidário ou pluripartidário, três ou mais partidos concorrem pelo poder, sendo considerado, em tese, o modelo mais democrático, dada a maior diversidade de opinião. Por sua vez, no pluripartidarismo, inevitavelmente, o partido vencedor se sustenta no poder por meio de negociações para viabilizar o exercício do seu governo.

A história dos partidos brasileiros é marcada pela transição de sistemas partidários. Relata Coêlho (2018) que, declarada a independência do Brasil e inaugurado o Império, formalmente não se constatava a existência de partidos políticos organizados, mas sim grupos que partilhavam interesses em comum, como: monarquistas - apoiadores da centralização do poder no imperador - e liberais - opositores que defendiam a menor concentração desse poder. Iniciado o período regencial, ante a abdicação de D. Pedro I, foram criados o Partido Liberal e o Partido Conservador, que disputavam a liderança política sujeitando-se ao Poder Moderador de D. Pedro II, em governo parlamentarista. Por volta de 1873, surge o Partido Republicano, opondo-se à monarquia e propondo a instituição de uma república federativa.

Estabelecido o período republicano, durante a Primeira República (1889-1930), ganham vez os partidos republicanos de domínio estadual como o paulista, o mineiro e o rio-grandense. Chegada a Revolução de 1930, colocando fim à República Velha, aparecem o Partido Democrático, em São Paulo; o Partido Nacionalista, em Minas Gerais e o Partido Libertador, no Rio Grande do Sul (STRECK e MORAIS, 2014), assim como a criação do Partido Comunista do Brasil, em 1922.

Iniciado o governo de Getúlio Vargas (1930-1945), tem-se, em 1932, a formação da Ação Integralista Brasileira - AIB, inspirada no fascismo e coordenada por Plínio Salgado, assim como, nesse mesmo ano, foi criado o primeiro Código Eleitoral brasileiro. Mais à frente, em 1935, surgiu a Aliança Nacional Libertadora - ANL, liderada por Júlio Prestes, insurgindo-se contra o governo Vargas e à Ação Integralista Brasileira. Em 1937, outorgada a Constituição "Polaca", a Justiça Eleitoral foi extinta, os partidos políticos foram abolidos, as eleições foram suspensas e o presidente passou a ser eleito de forma indireta. No fim da 
Era Vargas, em 1945, um novo Código Eleitoral foi elaborado trazendo consigo a inovação da obrigatoriedade de partidos políticos de caráter nacional, ${ }^{25}$ bem como, a proibição de candidaturas avulsas ${ }^{26}$ (COÊLHO, 2018).

Com a redemocratização (1946-1964), novos partidos políticos despontaram, com destaque para a União Democrática Nacional - UDN, o Partido Social Democrático - PSD e o Partido Trabalhista Brasileiro - PTB disputando o embate político (COÊLHO, 2018). Ao lado destes, também surgiram pequenos partidos como PSP, PL, PDC, PRT, PTN e outros (STRECK; MORAIS, 2014).

O golpe de 1964 iniciou a ditadura militar no país e os partidos políticos existentes foram aniquilados pelo Ato Institucional $\mathrm{n}^{\circ} .2 / 1965$. Em 1966, foram instituídos dois partidos políticos que disputavam o poder: a Aliança Renovadora Nacional - ARENA, conservador e de apoio à ditadura militar, e o Movimento Democrático Brasileiro - MDB, integrado por liberais e de resistência ao regime ditatorial (COÊLHO, 2018). Claramente a existência desses partidos era apenas uma tentativa de mascarar a ditadura, aparentando eles instrumentos democráticos.

No vagaroso processo de democratização do país, decidiu-se pela extinção do bipartidarismo até então cultivado. A Lei $n^{\circ}$. 6.767, promulgada em 1979, extinguiu os partidos ARENA e MDB, e passou a regulamentar todo o processo de criação dos partidos políticos de 1980 a 1995 . Uma de suas medidas foi o estabelecimento do prazo de 180 dias para que novos partidos políticos fossem organizados (NICOLAU, 1996).

Com o nascimento da Constituição da República de 1988, empenhada em garantir a liberdade de ideias para a nova democracia que se construiria, as restrições políticas antes vivenciadas foram superadas alçando-se, no artigo $1^{\circ}$. da CF/88, o pluralismo político como um dos fundamentos da República Federativa, reconhecendo-se a diversidade de pensamento e opiniões como inerentes ao Estado Democrático.

Nesse sentido, Adriano Sant'Ana Pedra (2018, p. 309) reforça que, em uma sociedade politicamente pluralista, os indivíduos percebem a realidade de maneira diversificada e é preciso que haja respeito a essa diferença e às liberdades individuais, cabendo à "Constituição assegurar o espaço próprio do pluralismo político, bem como, o adequado funcionamento dos mecanismos democráticos a fim de ser estabelecida uma forma racional de coexistência".

Reconhecidas as transgressões ao direito de representação em vários momentos da história brasileira, como demonstrado, a Constituição Federal de 1988, no artigo 17, assegurou a livre criação, fusão, incorporação e extinção dos partidos políticos, resguardando a soberania nacional, o regime democrático, o pluripartidarismo e os direitos fundamentais da pessoa humana.

Ocorre que, nos últimos anos, o número de partidos políticos vem crescendo de forma desenfreada no Brasil. De acordo com dados do Tribunal Superior Eleitoral, ${ }^{27}$ existem cerca de 35 partidos registrados no órgão. O mencionado Tribunal ${ }^{28}$ noticiou que, no início do

25 Artigo $110, \S 1^{\circ}$. Só podem ser admitidos a registro os partidos políticos de âmbito nacional.

26 Artigo 39. Somente podem concorrer às eleições candidatos registrados por partidos ou alianças de partidos.

27 Tribunal Superior Eleitoral. In: http://www.tse.jus.br/partidos/partidos-politicos/registrados-no-tse. Acesso em: 9 mai. 2019.

28 Tribunal Superior Eleitoral. In: http://www.tse.jus.br/imprensa/noticias-tse/2018/Janeiro/brasil-tem-73-partidos-em-processo-de-formacao. Acesso em: 9 mai. 2019. 
ano de 2018, o número de partidos políticos em processo de formação totalizava 73). Esse número corresponde às legendas que comunicaram ao TSE já terem obtido o registro civil em cartório, que é um dos requisitos exigidos para a criação de partidos políticos.

Num primeiro momento, pode parecer que o número volumoso de partidos políticos representa uma multiplicidade de vontades da sociedade e que a democracia de fato existe e está sendo praticada de forma exitosa, no entanto, como Bernardino (2018, p. 61-62) provoca, "[...] sob o manto do pluralismo político e do pluripartidarismo, tal instrumento de participação política vem sendo utilizado de forma vil e acintosa por alguns dirigentes partidários, especialmente na forma de barganha política e de rentabilidade [...]", mais parece um desvirtuamento do papel das instituições partidárias, que acaba por enfraquecer a democracia. Para Marcos Coêlho (2018), atualmente, os maiores desafios que permeiam os partidos políticos estão ligados à representatividade e ao desempenho do sistema democrático, já que os partidos políticos brasileiros têm assumido uma estrutura meramente cartorial, que rejeita a essência democrática da instituição partidária.

Desse modo, é inegável que o sistema pluripartidário proporciona para a sociedade uma maior gama de opções para identificação, permitindo que o cidadão escolha o partido político com o qual seus ideais convirjam, mas sendo imprescindível que as implicações do pluripartidarismo sejam plenamente conhecidas por aqueles que votam.

\section{CONSIDERAÇÕES FINAIS}

O estudo dos elementos fundamentais do presidencialismo desenvolvido em solo brasileiro - federalismo, sistema eleitoral proporcional e de lista aberta e multipartidarismo - permite melhor compreender o porquê de a coalizão ser a principal característica do presidencialismo no nosso país.

A forma como o federalismo se adaptou às questões brasileiras acabou por, de certa forma, deturpá-lo. A inspiração norte-americana atrelada à esperança de que apenas o federalismo, por si só, seria capaz de trazer a prosperidade à nossa nação, fez que essa forma de Estado fosse implantada aqui. Entre idas e vindas, de momentos democráticos a intervalos ditatoriais, o que se observa ao longo da história brasileira é essa pretensão de federação que, na prática, foi atingida de modo muito precário.

Atualmente, a Constituição Federal deixou pouco espaço para a autonomia política e orçamentária dos Estados-membros e municípios, lhes restando uma margem bastante restrita para a promoção de iniciativas específicas. Além disso, esses entes também se veem limitados pelas decisões do STF, o qual, inclusive, entende que as constituições e legislações estaduais devem ser, em sua grande medida, repetição obrigatória do texto constitucional.

Ainda que se argumente a existência de competências específicas (residuais) dos Estados-membros e municípios, assim como, de competências concorrentes e comuns, o fato é que sobra pouco espaço para o exercício desses poderes, especialmente quando se tem um cenário de concentração de atribuições e recursos nas mãos da União. Acrescente-se ainda a realidade heterogênea que os Estados-membros guardam entre si em termos socioeconômicos, outro fator de dependência dos repasses de verbas federais. 
Por conta dessas questões, é que é muito utópico falar em "federalismo cooperativo", quando, na verdade, o que se tem é uma grande diferença entre as capacidades dos Estados-membros para implementarem políticas públicas, decorrentes das enormes desigualdades financeiras, técnicas, administrativas e pela ausência de mecanismos constitucionais ou institucionais que estimulem a cooperação, o que torna o sistema extremamente competitivo.

O sistema eleitoral proporcional de lista aberta, por sua vez, apesar de suas reconhecidas vantagens como a igualdade no peso dos votos, a promoção da representação das minorias, dinamicidade que fomenta o pluralismo político, em solo tupiniquim, acabou por deixar as suas desvantagens assumirem o protagonismo. Diz-se isso porque o pluralismo político, quando mal administrado, pode gerar fraqueza e instabilidade política, por meio de fusões partidárias oportunistas e que refletem no eleitorado pouca confiança. Essa circunstância, atrelada à complexidade das técnicas de contagem de votos e da distribuição de cadeiras nas Casas Legislativas - que permite, inclusive, que um candidato que tenha recebido um grande número de votos, "puxe" (eleja) outros candidatos do seu partido, com votação inexpressiva - e a deficiência de educação política da população, só aumentam a incerteza dos resultados.

Em relação ao multipartidarismo, deve-se reconhecer que, no contexto da Constituição da República de 1988, ele surge empenhado em garantir a liberdade de ideias para a nova democracia que se levantava, alçando o pluralismo político a um dos fundamentos da República Federativa, reconhecendo-se a diversidade de pensamento e opiniões como inerentes ao Estado Democrático. Com base nisso, o texto constitucional assegurou a livre criação, fusão, incorporação e extinção dos partidos políticos, resguardando a soberania nacional, o regime democrático, o pluripartidarismo e os direitos fundamentais da pessoa humana.

Ocorre que nos últimos anos o número de partidos políticos vem crescendo de forma desenfreada no Brasil, indicando que a criação de instituições dessa natureza seja pretensiosamente utilizada por alguns dirigentes partidários, visando à barganha política e à obtenção de caixa para as suas legendas. Essa forma de proceder denota o desvirtuamento do papel das instituições partidárias e gera o enfraquecimento da democracia pelo excesso de fragmentariedade.

Cientes das peculiaridades desses elementos, já é possível entender por que a coalizão é encarada como característica inerente ao presidencialismo brasileiro. De fato, a coalizão, entendida como a realização de alianças, é algo presente nos movimentos políticos democráticos em qualquer parte do mundo. Entende-se principalmente que, diante das características brasileiras, da profunda heterogeneidade entre as regiões, do passado de equívocos e incertezas e das dificuldades financeiras que o país sempre enfrentou, é perfeitamente compreensível a necessidade de acordos entre o chefe do Poder Executivo e uma pretensa base aliada, com o fim de colocar em prática a sua agenda nacional. No entanto, é imprescindível que se rechace toda e qualquer coalizão destinada a fins escusos e antirrepublicanos, de modo que o julgamento dessas circunstâncias parte do conhecimento dos elementos básicos do presidencialismo no Brasil, como se examinou neste estudo. 


\section{REFERÊNCIAS}

ABRANCHES, Sérgio Henrique. O presidencialismo de coalizão: o dilema institucional brasileiro. In: Revista Dados, v. 31, nº. 1, 1988, p. 5-32.

ABRANCHES, Sérgio Henrique. Os ciclos do presidencialismo de coalizão. Ecopolítica Ensaios, 2014. Disponível em: http://www.academia.edu/6411308/Os_Ciclos_do_Presidencialismo_de_Coaliz\%C3\%A3o Acessado em: 18 mar. 2020.

BARACHO, José Alfredo de Oliveira. A federação e a revisão constitucional. As novas técnicas dos equilíbrios constitucionais e as relações financeiras. A cláusula federativa e a proteção da forma de estado na Constituição de 1988. R. Dir. Adm., Rio de Janeiro, 202: 49-60, out./dez. 1995. Disponível em: http://bibliotecadigital.fgv.br/ojs/index.php/rda/article/view/46617/46351. Acesso em: 18 out. 2020.

BARCELlOS, Ana Paula de. Curso de direito constitucional. Rio de Janeiro: Forense, 2018.

BASTOS, Celso Ribeiro. Curso de Direito Constitucional, 22. ed. rev. atual. São Paulo: Malheiros, 2010.

BERCOVICI, Gilberto. Dilemas do estado federal brasileiro. Porto Alegre: Livraria do advogado Ed., 2004.

BONAVIDES, Paulo. Ciência Política, 10. ed., 9ª Tiragem, rev. e atual. São Paulo: Malheiros, 2001.

BRASIL. Código Eleitoral brasileiro. Disponível em: < http://www.planalto.gov.br/ccivil_03/LEIS/L4737.htm> Acessado em: 20 mar. 2020.

BRASIL. Constituição (1988). Constituição da República Federativa do Brasil. Brasília, DF, 1988. Disponível em: < http://www.planalto.gov.br/ccivil_03/constituicao/constituicao.htm> Acessado em: 20 mar. 2020.

CAMARÃO, Felipe Costa. Sistemas eleitorais brasileiros. Pará de Minas, MG: Editora Virtualbooks, 2012.

CARVALHO, Márcia Haydée Porto de; MAIA, Maicy M. M. Principais características do Poder Executivo Americano. In: RAMOS, Paulo Roberto Barbosa (Org.). Introdução ao Direito Constitucional Americano. Curitiba: CRV, 2019.

COÊLHO, Marcus Vinicius Furtado. Democracia e partidos políticos. In: FUX, Luiz; PEREIRA, Luiz Fernando Casagrande; AGRA, Walber de Moura (Coord.); PECCININ, Luiz Eduardo (Org.). Direito Partidário. Belo Horizonte: Fórum, 2018, p. 15-22 (Tratado de Direito Eleitoral, v. 2). 
DALLARI, Dalmo de Abreu. Elementos de Teoria Geral do Estado, 31. ed. São Paulo: Saraiva, 2012.

FERREIRA FILHO, Manoel Gonçalves. Curso de direito constitucional, 37. ed. rev. e atual. São Paulo: Saraiva, 2011.

HAMILTON, Alexander; MADISSON, James; JAY, John, e Cidadãos de Nova York. O federalista. Rio de Janeiro, Typ. Imp. e Const. de J. Villeneuve e Comp, 1840. Disponível em: <http://bd.camara.gov.br/bd/handle/bdcamara/17661\#> Acessado em: 25 out. 2020.

KELSEN, Hans. A democracia, 2. ed. São Paulo: Martins Fontes, 2000.

LIMONGI, Fernando. A democracia no Brasil: presidencialismo, coalizão partidária e processo decisório. Novos estud. - CEBRAP, São Paulo, n. 76, p. 1741, nov. 2006. Disponível em: http://www.scielo.br/scielo.php?script=sci_arttext\&pi$\mathrm{d}=\mathrm{S} 0101-33002006000300002 \& \operatorname{lng}=\mathrm{en} \& \mathrm{nrm}=$ iso. Acesso em: 19 mar. 2020. https://doi. org/10.1590/S0101-33002006000300002.

MACHADO, Raquel Cavalcanti Ramos. Direito eleitoral, 2. ed. rev., atual. e ampl. São Paulo: Atlas, 2018.

MAINWARING, Scott. Democracia Presidencialista multipartidária: o caso do Brasil. Lua Nova, São Paulo, n. 28-29, abr. 1993. Disponível em: http://www.scielo.br/scielo.php?script=sci_arttext\&pid=S0102-64451993000100003. Acesso em: $1^{\text {o }}$. abr. 2019.

MASSON, Nathalia. Manual de direito constitucional, 4. ed. rev. ampl. e atual. Salvador: JusPODIVM, 2016.

MEDEIROS E ALBURQUERQUE, José Joaquim de Campos de. Parlamentarismo e presidencialismo no Brasil. Rio de Janeiro: Calvino Filho, 1932.

NICOLAU, Jairo Marconi. Multipartidarismo e democracia: um estudo sobre o sistema partidário brasileiro. Rio de Janeiro: Editora Fundação Getúlio Vargas, 1996.

NICOLAU, Jairo Marconi. Sistemas Eleitorais. Rio de Janeiro: Fundação Getúlio Vargas, 2004.

PÉREZ-LIÑAN, Aníbal. ¿Juicio político o golpe legislativo? Sobre las crisis constitucionales en los años noventa. Revista América Latina, Hoy, n. 26 de dezembro de 2000, p. 67-74. Disponível em: https://revistas.usal.es/index.php/1130-2887/article/view/2702. Acesso em: 18 out. 2020.

RAMOS, Paulo Roberto Barbosa. Federalismo e descentralização territorial em perspectiva comparada: os sistemas do Brasil e da Espanha. Porto Alegre: S.A. Fabris, 2012.

REIS, Natália de Jesus Silva. O sistema constitucional americano e a ficção de superioridade democrática. In: RAMOS, Paulo Roberto Barbosa (Org.). Introdução ao Direito Constitucional Americano. Curitiba: CRV, 2019. 
RODRIGUES, Lilian Segnini; CARVALHO, Joelson Gonçalves de; FERRO, Samira Cecília Custódio; DANINI, Thiago Sentanin; MINOTTO, Ana Aparecida Pires; FAZZANI, Rosângela Aparecida Pereira. RODRIGUES, CARVALHO, FERRO, DANINI, MINOTTO e FAZZANI. Presidencialismo de coalizão: uma análise do impeachment da ex-presidenta Dilma Rousseff à luz da ruptura com sua base aliada. $15^{\circ}$ Congresso Nacional de Pesquisadores. UNICEP 2017. Anais: Pesquisa, o seu diferencial. Disponível em: $<$ https://www. academia.edu/36337140/Presidencialismo_de_Coaliz\%C3\%A3o_Uma_an\%C3\%A1lise_ do_impeachment_da_ex-presidenta_Dilma_Rousseff_a_luz_da_ruptura_com_sua_base aliada> Acessado em: 19 mar. 2020.

SANT'ANA PEDRA, Adriano. Comentário ao artigo $1^{\circ}$, inciso V. In: CANOTILHO, J. J.

Gomes; MENDES, Gilmar F.; SARLET, Ingo W.; STRECK, Lenio L. (Coords.). Comentários à Constituição do Brasil, 2. ed. São Paulo: Saraiva/Almedina, 2018, p. 304-310.

SCHNEIDER, Sergio; SCHIMITT, Cláudia Job. O uso do método comparativo nas Ciências Sociais. Cadernos de Sociologia, Porto Alegre, v. 9, p. 49-87, 1998.

SILVA, José Afonso da Silva. Curso de direito Constitucional, 25. ed. rev. e atual. São Paulo: Malheiros, 2006.

SOUZA, Celina. Federalismo, Desenho Constitucional e Instituições Federativas no Brasil pós-1988. Rev. Sociol. Polít., Curitiba, 24, jun. 2005, p. 105-121.

STRECK, Lenio Luiz; MORAIS, José Luiz Bolzan. Ciência política e teoria do estado, 8. ed. rev. e atual. Porto Alegre: Livraria do Advogado Editora, 2014.

\section{DAdOS DAS AUTORAS}

\section{Maicy Maia}

Advogada licenciada inscrita na OAB/MA, assessora de Promotor de Justiça no Ministério Público do Maranhão. Mestre pela Universidade Federal do Maranhão - UFMA. maicymaia@gmail.com

\section{Kassianne Mendes Silva}

Bacharel em Direito pela Universidade Federal do Maranhão - UFMA. kassianne_ms@ hotmail.com

Submetido em: 31-7-2020

Aceito em: 28-10-2020 